\title{
Desenvolvimento inicial de mudas de moringa oleífera Lam submetidas a diferentes substratos
}

\author{
Initial development of seedlings of moringa oleifera \\ Lam submitted to different substrates
}

\begin{abstract}
Wallyson Francisco Lopes da Silva ${ }^{1}$, Everton Sebastião do Nascimento ${ }^{1}$, João Raphael Lima Avelino ${ }^{1}$, Joan Jobson de Almeida de Amorim ${ }^{1}$, Pedro Carvalho Vieira Cavalcante ${ }^{1}$, Nathanyel Ewertthon Alves dos Santos ${ }^{1}$, Denise Maria Santos ${ }^{2}$, Camila Alexandre Cavalcante de Almeida ${ }^{1}$, Andréa de Vasconcelos Freitas Pinto ${ }^{1}$, Maria José de Holanda Leite ${ }^{2 *}$
\end{abstract}

\section{RESUMO}

O objetivo do trabalho foi investigar qual a melhor concentração de substratos para produção de mudas de Moringa Oleifera Lam, com a finalidade de se obter plantas mais saudáveis, vigorosas e resistentes. O experimento foi conduzido em casa de vegetação na unidade da Embrapa Tabuleiro Costeiro, localizado no Campus de Engenharias e Ciências Agrárias - CECA/UFAL, Rio Largo, AL. Foi realizado o delineamento inteiramente casualizado (DIC) com 7 tratamentos: T0 - 100\% solo (testemunha); $\mathrm{T} 1-$ solo $+10 \%$ de esterco ovino; $\mathrm{T} 2-$ solo $+20 \%$ de esterco ovino; $\mathrm{T} 3-$ solo $+33 \%$ de esterco ovino; $\mathrm{T} 4-$ solo $+10 \%$ de borra de café; $\mathrm{T} 5$ - solo $+20 \%$ de borra de café; $\mathrm{T} 6$ - solo $+33 \%$ de borra de café, com cinco repetições, totalizando 35 saquinhos de polietileno, com volume de 3litros, foi utilizada análise de regressão quadrática e cúbica, adotando-se o nível de 5\% de significância. Ao contrário do esperado, as mudas produzidas em ambos substratos não apresentam maiores valores. Em relação ao substrato contendo esterco ovino, foi observado que sua utilização em maiores concentrações prejudica sua decomposição e consequentemente a disponibilidade de nutrientes para as plantas. O substrato contendo borra de café, mostrou mais inviável e que sua utilização "in natura" acidifica o solo e torna lenta a mineralização dos nutrientes. Assim é possível recomendar a produção de mudas de Moringa oleifera Lam com substrato de esterco ovino na concentração de $20 \%$.

Palavras-chave: Borra de café; Esterco ovino; Reflorestamento.

\begin{abstract}
The objective of the work was to investigate the best concentration of substrates for the production of Moringa Oleifera Lam seedlings, with the use of obtaining healthier, more vigorous and resistant plants. The experiment was conducted in the greenhouse at the Embrapa Tabuleiro Costeiro unit, located at the Campus of Engineering and Agricultural Sciences - CECA / UFAL, Rio Largo, AL. It was carried out or outlined by randomization (DIC) with 7 tests: T0 - 100\% solo (witness); T1 - soil + 10\% sheep manure; T2
\end{abstract}

\footnotetext{
${ }^{1}$ Universidade Federal de Alagoas, Campus de Engenharias e Ciências Agrárias CECA/UFAL, BR 104, Km 85, s/n, Rio Largo - AL, Brasil.

2 Instituto Dom José de Educação e Cultura (IDJ/UVA). Av. Heráclito Graça - Centro, Fortaleza/CE, nº 400- CEP: 60140-060, Brasil *E-mail: maryholanda@gmail.com
} 
- soil $+20 \%$ sheep manure; $\mathrm{T} 3-$ soil $+33 \%$ of sheep manure; $\mathrm{T} 4$ - soil $+10 \%$ coffee coffee; $\mathrm{T} 5$ - soil + $20 \%$ coffee coffee; T6 - soil $+33 \%$ of coffee coffee, with five replications, totaling 35 polyethylene bags, with a volume of 3 liters, was used for the analysis of quadratic and cubic regression, adopting the level of $5 \%$ of significance. Contrary to expectations, as seedlings produced on both substrates do not have higher values. Regarding the substrate that contains sheep manure, it was observed that its use in greater damages impairs its decomposition and, consequently, the availability of nutrients for plants. The substrate that contains coffee grounds, proved to be more impractical and that its "in natura" use acidifies or becomes slow and mineralizes nutrients. Therefore, it is possible to recommend the production of Moringa oleifera Lam seedlings with sheep manure substrate with a concentration of $20 \%$.

Resumo no segundo idioma, com as mesmas regras e a mesma formatação do anterior.

Keywords: Coffee grounds; Sheep manure; Reforestation.

\section{INTRODUÇÃO}

A produção de Moringa oleifera Lam vem se destacando pelo fato desta espécie apresentar uma grande importância cotidiana, considerados por muitos produtores como "planta milagrosa" devido a sua ampla utilização em áreas industriais, medicinais e na produção de biomassa [1]. Para uma alta produção de mudas de qualidade desta espécie é necessário que haja um nível de eficiência dos substratos, uma vez que, a germinação de sementes, iniciação radicular e enraizamento de estacas, formação do sistema radicular e parte aérea, está associada com a aeração, drenagem, retenção de água, disponibilidade balanceada de nutrientes presentes nos substratos, além do manejo e a condução do viveiro [2], além de aumentar a porcentagem de sobrevivência no campo, evita os custos da implantação e o replantio de mudas [3].

Sabe-se que o substrato é um dos fatores mais relevantes no desenvolvimento inicial, pelo fato de ser o meio em que se desenvolvem as raízes das plantas cultivadas fora do solo "in situ", podendo ainda regular a disponibilidade de nutrientes e de água [4]. A incorporação de resíduos orgânicos reduz o custo de produção e possíveis danos decorrentes do acúmulo desse material no ambiente, além de inserir uma matéria orgânica rica em nutrientes [5]. Vale destacar que o substrato ainda, influência na nutrição e crescimento das plantas após iniciarem a fotossíntese, as características físicas, químicas e biológicas do mesmo vão influenciar na oxigenação, retenção de umidade e ataque de patógenos [6].

Para a composição de substrato de mudas de espécies arbóreas, recomenda-se a incorporação de "esterco ovino" e a "borra de café", pelo fato de estes serem excelentes fornecedores de nutrientes. A utilização dos mesmos também se justifica, pelo fato de ser uma alternativa sustentável, uma vez que com a sua utilização é possível reduzir seu 
impacto no ambiente e de certa forma melhorar o ecossistema agrícola [7].

Assim, o objetivo do trabalho foi investigar qual a melhor concentração de substratos para produção de mudas de Moringa Oleifera Lam, com a finalidade de se obter plantas mais saudáveis, vigorosas e resistentes. Assumindo que a incorporação de $33 \%$ de esterco ovino (EO) e menores concentrações de borra de café (BC) proporciona condições ideais para produção de mudas de espécies arbóreas, com as seguintes hipóteses: a) de que no substrato contendo $33 \%$ de EO as mudas de Moringa Oleifera Lam apresentarão maior desenvolvimento inicial; b) e que em baixas concentrações de borra de café (BC) as mudas mostrariam maior desenvolvimento inicial. Caso isso seja verdade, espera-se maiores valores de: área foliar (AF), teor de matéria seca da folha (TMSF), do caule (TMSC) e da raiz (TMSR) e total(TMST), altura (H), diâmetro do caule (DC) e comprimento das raízes (CR) no substrato contendo 33\% de EO e nas menores doses de BC.

\section{MATERIAL E MÉTODOS}

Área de estudo

O experimento foi conduzido em casa de vegetação na unidade da Embrapa Tabuleiro Costeiro, localizado no Campus de Engenharias e Ciências Agrárias - CECA, da Universidade Federal de Alagoas - UFAL, município de Rio Largo, Brasil, região norte do estado de Alagoas, situado a $9^{\circ} 28^{\text {ee }} 02^{\text {ece }}$ de latitude e $35^{\circ} 49^{\text {ee }} 65^{\text {cee }}$ de longitude com altitude de $135 \mathrm{~m}$. O trabalho foi desenvolvido no período de 30 de maio a 01 de agosto de 2019, com duração de 63 dias.

\section{Coleta de solo, sementes e preparo do substrato}

O solo foi coletado na área experimental do Centro de Ciências Agrárias - CECA, classificado na literatura como Latossolo Amarelo Coeso Argissolico, de textura franca arenosa, utilizada no experimento para compor os substratos. Para o experimento foram utilizados o esterco de ovino e borra de café (in natura), os quais foram peneirados e destorroados para processo de mistura ao solo, obtidos por meio de doação da empresa Planta \& Cia localizada no município de Atalaia/AL. Após o preparo dos substratos, os mesmos foram colocados em sacos de polietileno com volume de 3 litros e retiradas amostras dos tratamentos para a análise química, realizada no Laboratório de Solo, Água e Planta, localizado no CECA-UFAL.

As sementes de Moringa oleífera Lam foram coletadas nas árvores matrizes da 
cidade de Maceió, na região do tabuleiro, ficaram armazenadas por três meses em sacos de papel em temperatura ambiente e não houve a necessidade do processo de quebra da dormência. Desta forma, a semeadura ocorreu no dia 30 de maio de 2019. Decorridos 10 dias de plantio foram feitas retiradas manuais para eliminar o crescimento de plantas consideradas invasoras. Posterior a semeadura, foram realizadas irrigações diárias, até o $16^{\circ}$ dia pós plantio, ao término desse período, foram feitas regas a cada dois dias totalizando 40 irrigações.

\section{Tratamentos}

Os tratamentos consistiram em: T0 $-100 \%$ solo (testemunha); T1 - solo $+10 \%$ de esterco ovino; $\mathrm{T} 2-$ solo $+20 \%$ de esterco ovino; $\mathrm{T} 3-$ solo $+33 \%$ de esterco ovino; $\mathrm{T} 4-$ solo $+10 \%$ de borra de café; $\mathrm{T} 5-$ solo $+20 \%$ de borra de café; T6 - solo $+33 \%$ de borra de café. As proporções adicionadas ao solo foram 9:1 para o T1 e T4 sendo 9 porções de solo para 1 de esterco ovino e pó de café. 8:2 para T2 e T5, 3:1 para T3 e T6; 8 porções de solo para 2 de esterco ovino; 3 de solo para 1 de esterco ovino. 9:1 para o T1, 8:2 para T2 e 3:1 para T3, sendo 9 porções de solo para 1 de esterco ovino; 8 porções de solo para 2 de esterco ovino; 3 de solo para 1 de esterco ovino. Analisados no esquema fatorial de: 7 tratamentos $X 5$ repetições, totalizando 35 sacos de $3 \mathrm{~L}$, contendo substrato para o experimento. Em cada saco, foram plantadas 3 sementes com uma profundidade de $1 \mathrm{~cm}$, totalizando 105 . Os sacos foram colocados de forma aleatório no delineamento inteiramente casualizado (DIC).

\section{Parâmetros avaliados}

Os parâmetros avaliados foram: altura $(\mathrm{H})$, área foliar (AF), diâmetro do caule (DC), comprimento da raiz (CR), teor de matéria seca da folha (TMSF), do caule (TMSC), da raiz (TMSR) e teor de matéria seca total (TMST).

O caráter altura da planta e diâmetro do caule começaram a ser analisadas logo após a emergência das plantas com intervalos de oito dias, ocorrendo sempre no horário matutino 9:00hrs. Para altura, foi utilizada uma régua milimetrada graduada, medindo-se do solo até a inserção das folhas primárias; no diâmetro utilizou-se o instrumento paquímetro eletrônico. Ao decorrer de 63 dias, no final do experimento, as mudas foram retiradas dos sacos e fracionadas em parte aérea, caule e raiz, para então ser realizada analises finais. A área foliar foi mensurada através de um integrador de área foliar Li-Cor modelo LI- 3100C. Em seguida, determinado o comprimento das raízes com uma régua milimetrada, posterior a isso o material vegetal foi encaminhado para estufa de circulação 
forçado de ar, à temperatura de $65^{\circ} \mathrm{C}$ por 48 horas e pesadas em balança analítica para obtenção da massa seca.

\section{Análises de dados}

Inicialmente foi testada a normalidade dos dados, como os dados apresentaram-se normais foram realizados testes paramétricos. Para responder as hipóteses de que a) no substrato contendo $33 \%$ de EO as mudas de moringa apresentaram maior desenvolvimento inicial; b) e que em baixas concentrações de borra de café (BC) as mudas demonstrem maior desenvolvimento inicial, usou-se análises de regressão, adotando-se o nível de $(\mathrm{P}<0,05)$ de significância para ambas, tendo em vista que a regressão demonstra melhor a relação de concentração nos níveis de substrato com os parâmetros avaliados. Para realização da análise utilizou-se o programa estatístico Sisvar 5.6 .

\section{Análise química dos substratos}

Tabela 1. Análise química dos substratos utilizados na produção de mudas da Moringa.

Table 1. Chemical analysis of the substrates used in the production of Moringa seedlings

\begin{tabular}{|c|c|c|c|c|c|c|c|c|c|c|c|c|}
\hline \multirow[t]{2}{*}{ Trat. } & \multirow{2}{*}{$\begin{array}{l}\mathrm{pH} \mathrm{em} \mathrm{H}_{2} \mathrm{O} \\
1: 2,5\end{array}$} & \multirow{2}{*}{$\begin{array}{l}\text { M.O. }^{4} \\
\text { g.kg-1 }\end{array}$} & $\mathrm{P}^{(1)}$ & $\mathrm{K}^{(1)}$ & $\mathrm{Na}^{(1)}$ & $\mathrm{Al}^{(2)}$ & $\mathrm{H}+\mathrm{A}$ & $\mathrm{Ca}^{(2)}$ & $\mathrm{Mg}^{(2)}$ & $\mathrm{CT}$ & $\mathrm{TCt}$ & \multirow{2}{*}{$\begin{array}{c}\mathrm{V}^{(5)} \\
\%\end{array}$} \\
\hline & & & \multicolumn{4}{|c|}{$------\left(m g . \mathrm{dm}^{3}\right)----$} & \multicolumn{5}{|c|}{ 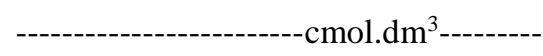 } & \\
\hline T0-Test. & 6,0 & 22,4 & 83 & 33 & 5 & 0,07 & 3,18 & 3,72 & 1,76 & 5,65 & 8,76 & 64 \\
\hline $\mathrm{T} 1$ & 6,7 & 26,3 & 156 & 43 & 15 & 0 & 1,74 & 6,82 & 2,32 & 9,32 & 11,06 & 67 \\
\hline $\mathrm{T} 2$ & 7,1 & 30,2 & 251 & 65 & 20 & 0 & 1,06 & 6,28 & 3,4 & 9,94 & 11 & 90 \\
\hline $\mathrm{T} 3$ & 7,6 & 42,3 & 171 & 60 & 20 & 0 & 1,08 & 4,1 & 3,53 & 8,28 & 9,36 & 88 \\
\hline $\mathrm{T} 4$ & 5, & 46 & 61 & 35 & 5 & 0,19 & 3,3 & 3,95 & 2,06 & 6,31 & 9,42 & 65 \\
\hline T5 & 5,4 & 51,6 & 54 & 190 & 30 & 0,14 & 3,93 & 2,6 & 2,17 & 5,53 & 9,32 & 58 \\
\hline T6 & 5,3 & 58,9 & 50 & 200 & 35 & 0,19 & 4,34 & 3,08 & 1,47 & 5,4 & 9,55 & 55 \\
\hline
\end{tabular}

* pH = Potencial Hidrogeniônico; $\mathrm{MO}=$ Matéria orgânica; $\mathrm{P}=$ Fósforo; $\mathrm{K}=$ Potássio; $\mathrm{Na}=\mathrm{Sódio} ; \mathrm{H}+\mathrm{Al}=$ Acidez total; $\mathrm{Ca}=$ Cálcio; $\mathrm{Mg}=$ Magnésio; $\mathrm{CTCe}=$ Capacidade de troca de Cátions efetiva; $\mathrm{CTCt}=$ Capacidade de troca de Cátions total; V= Saturação por Bases.

*Determinações: (1) Extrator de Mehlich-1; (2) Extrator de KCL 1,0 M; (3) Extrator de Acetato de cálcio a pH 7,0; (4) Método de Welkley-Black; (5) Saturação por bases.

\section{RESULTADOS}

\section{Esterco ovino (EO)}

\section{Altura (H) e diâmetro do caule (DC)}

$\mathrm{Na}$ variável altura $(\mathrm{H})$, a concentração de $20 \%$ de EO apresentou diferença $\mathrm{P}(<0,05)$ mostrando-se superior aos demais tratamentos aos 63 DAP (Figura 1A). O valor em altura deste tratamento foi de $46,34 \mathrm{~cm}$ enquanto que a testemunha (apenas solo) apresentou altura de $43,05 \mathrm{~cm}$, promovendo um incremento de $7,64 \%$ em $(\mathrm{H})$ para as 
mudas de moringa.

Examinando o diâmetro do caule (DC), a concentração de $20 \%$ de EO obteve melhor resultado comparado às dosagens de 10 e $33 \%$ deste substrato, com o valor de $9,06 \mathrm{~cm}$ de DC. Observando o gráfico na (Figura 1B) demonstrou diferença $\mathrm{P}(<0,05)$. O Alto coeficiente de determinação $R^{2}(0,997)$ indica alta relação de dependência entre a altura em função da quantidade de esterco no substrato.

Figura 1. Altura (A) e Diâmetro do caule (B) das plantas de Moringa oleíferaLam, submetidas a substratos com diferentes concentrações $(0,10,20$ e 33 \%), de esterco ovino (EO). Regressão com: **significativo $(\mathrm{P}<0,05)$.

Figure 1. Height (A) and stem diameter (B) of the Moringa oleiferaLam plants, submitted to substrates with different concentrations (0,10, 20 and 33\%), of sheep manure (EO). Regression with: ** significant $(\mathrm{P}<0.05)$.
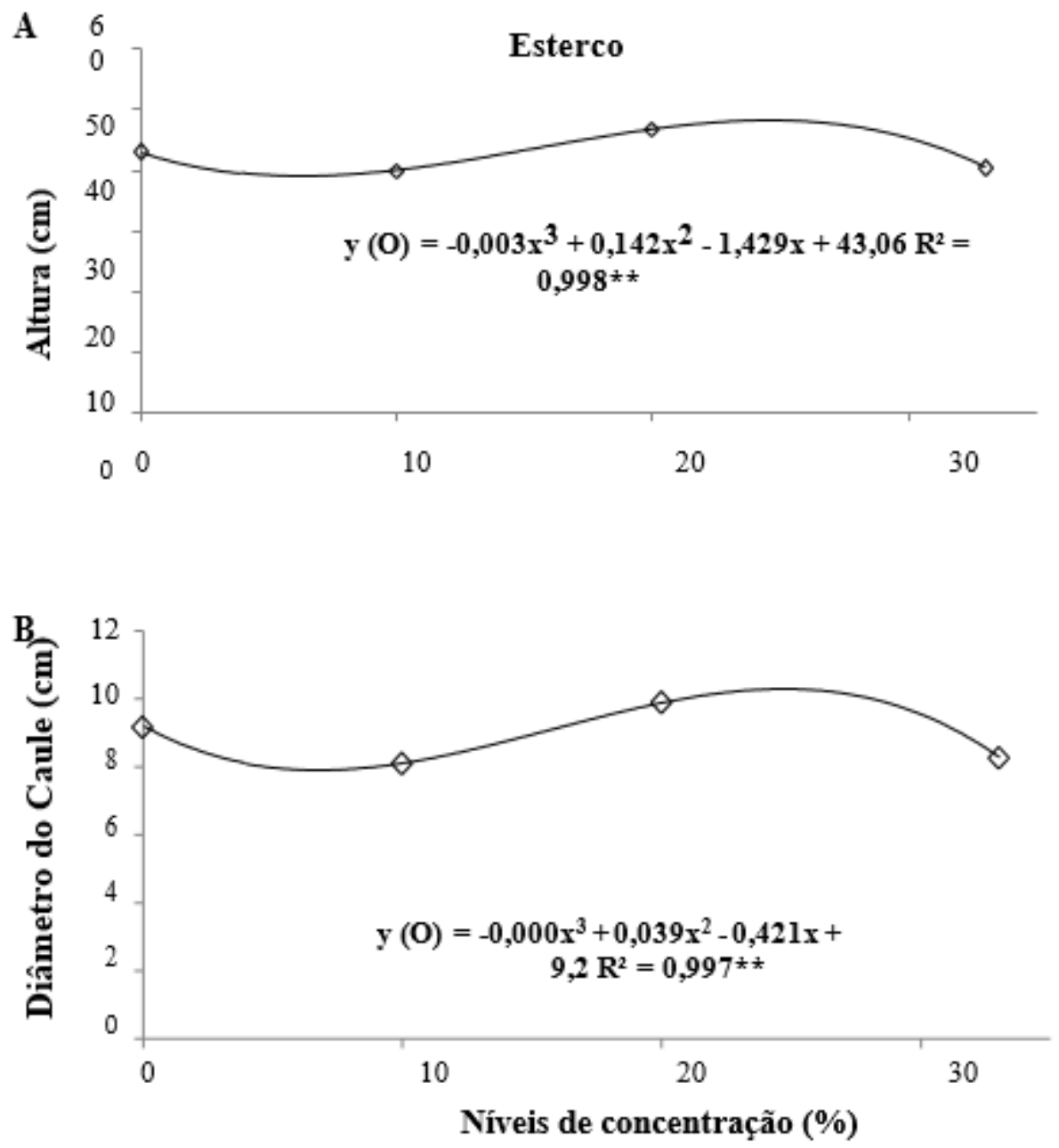

\section{Área foliar (AF) e comprimento de raiz (CR)}

$\mathrm{O}$ uso das concentrações de $\mathrm{EO}$ foi significativo $\mathrm{P}(<0,05)$ para a área foliar desta espécie, o resultado mais satisfatório foi obtido com a concentração de $20 \%$. A AF no 
tratamento sem adição de esterco ovino (testemunha) foi 10,02\% menor do que aquelas que receberam $20 \%$ de EO. Na análise de comprimento da raiz, a concentração de EO a 20\%, foi o melhor resultado, aumentou o CR em relação à testemunha em 33,33\%, demonstrando acréscimo de $5 \mathrm{~cm}$ em comprimento.

Figura 2. Área foliar (A) e comprimento da raiz (B) das plantas de Moringa oleífera Lam, submetidas substratos com diferentes concentrações (0, 10, 20 e 33\%), de esterco ovino (EO) regressão com **: significativo $(\mathrm{P}<0,05)$.

Figure 2. Leaf area (A) and root length (B) of the Moringa oleifera Lam plants, submitted to substrates with different concentrations $(0,10,20$ and 33\%), of sheep manure (EO) regression with **: significant $(\mathrm{P}<0.05)$.
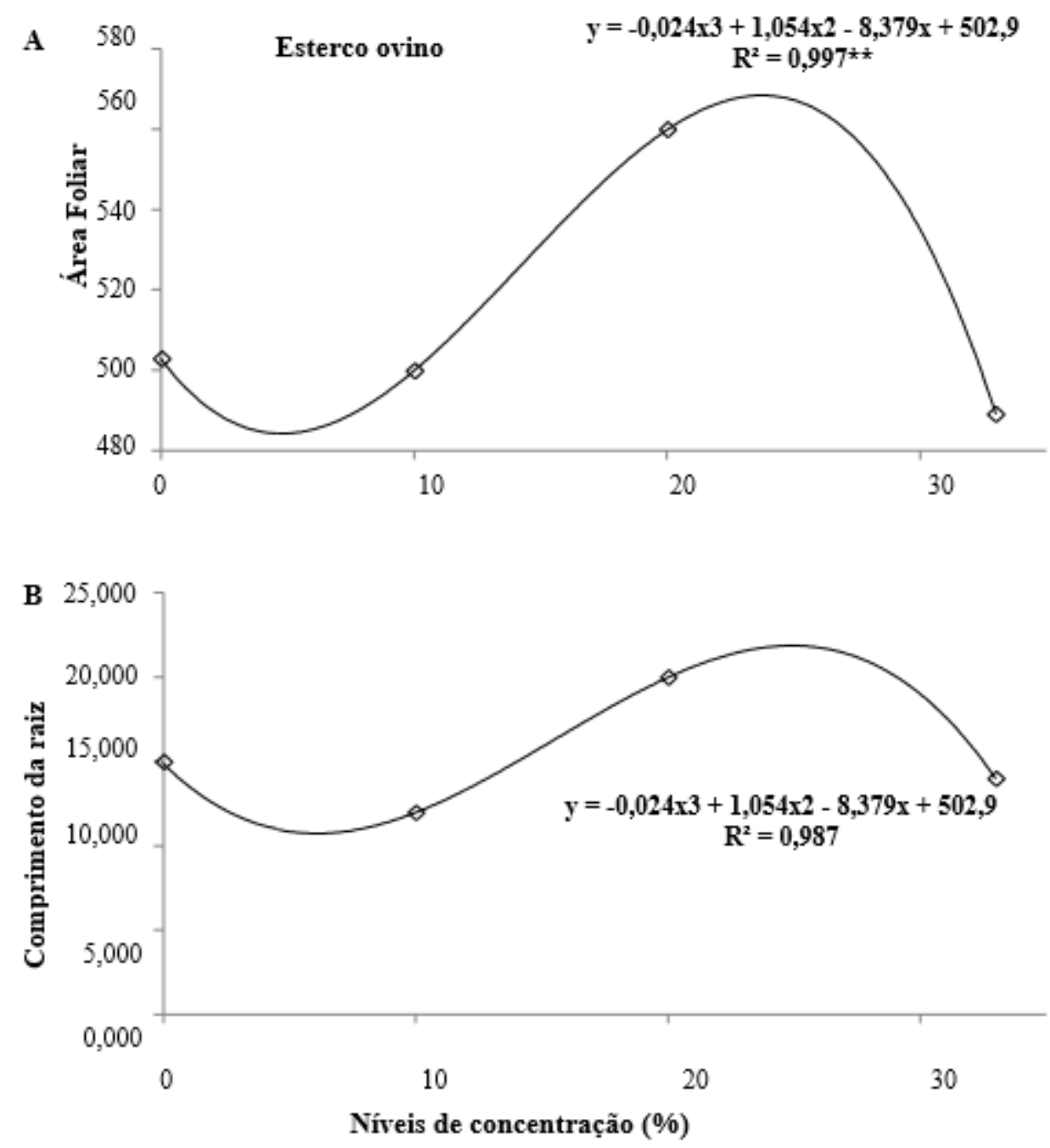

Teor de matéria seca do caule (TMSC), folha (TMSF) raiz (TMSR) e total (TMST)

Vale destacar que, os melhores resultados obtidos utilizando esterco ovino (EO) foi com a concentração de $20 \%$, demonstrando que essa dosagem incrementou 26,69\% na MSF em comparação com a testemunha, totalizando um acréscimo de 0,67g (Figura 3B). Semelhante ao ocorrido na TMSR com aumento de 55,09\% totalizando 2,10g a mais, 
quando comparado a testemunha; e o TMS do caule apesar de ter apresentado melhor resultado na testemunha ( $100 \%$ solo) com 2,95g, não afetou o TMST, que obteve resultados de acréscimo em 18,03\%, com índice de significância para o uso do substrato contendo 20\% d EO, $\mathrm{P}(<0,05)$ (Figura 3D).

Figura 3. Teor de matéria seca do caule (TMSC) (A), folhas (TMSF) (B), raiz (TMSR) (C) e matéria seca total (TMST) (D) de Moringa oleiferaLam, submetidas substratos com diferentes concentrações $(0,10,20$ e $33 \%)$, de esterco ovino. Regressão com **: significativo $(\mathrm{P}<0,05)$;

Figure 3. Dry matter content of the stem (TMSC) (A), leaves (TMSF) (B), root (TMSR) (C) and total dry matter (TMST) (D) of Moringa oleíferaLam, submitted to substrates with different concentrations $(0,10,20$ and 33\%) of sheep manure. Regression with **: significant $(\mathrm{P}<0.05)$.

A

\section{Esterco ovino}

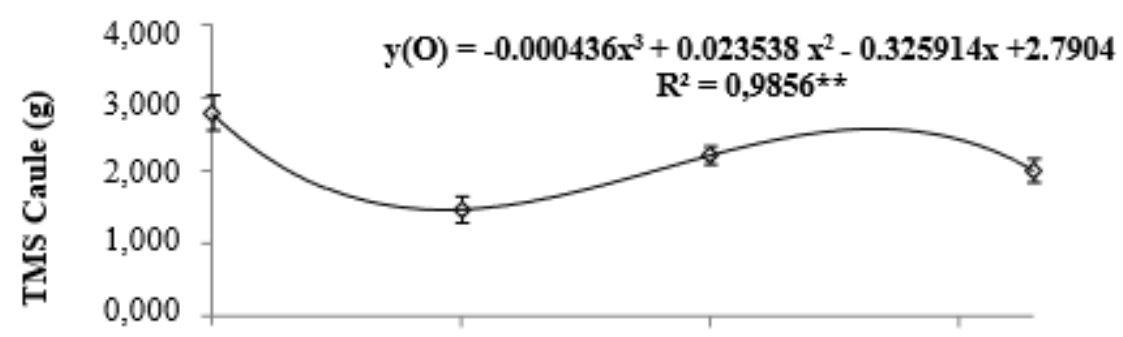

$\begin{array}{llll}0 & 10 & 20 & 30\end{array}$

B

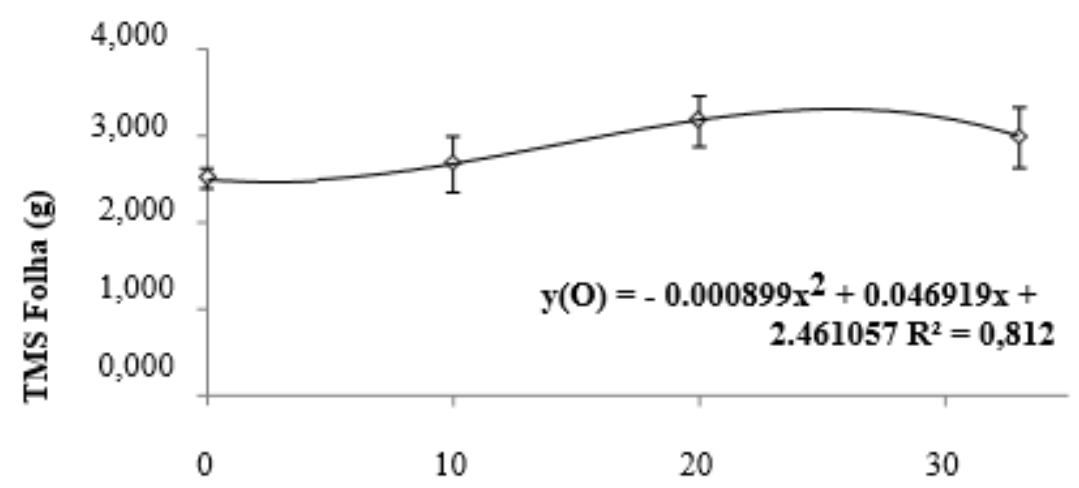



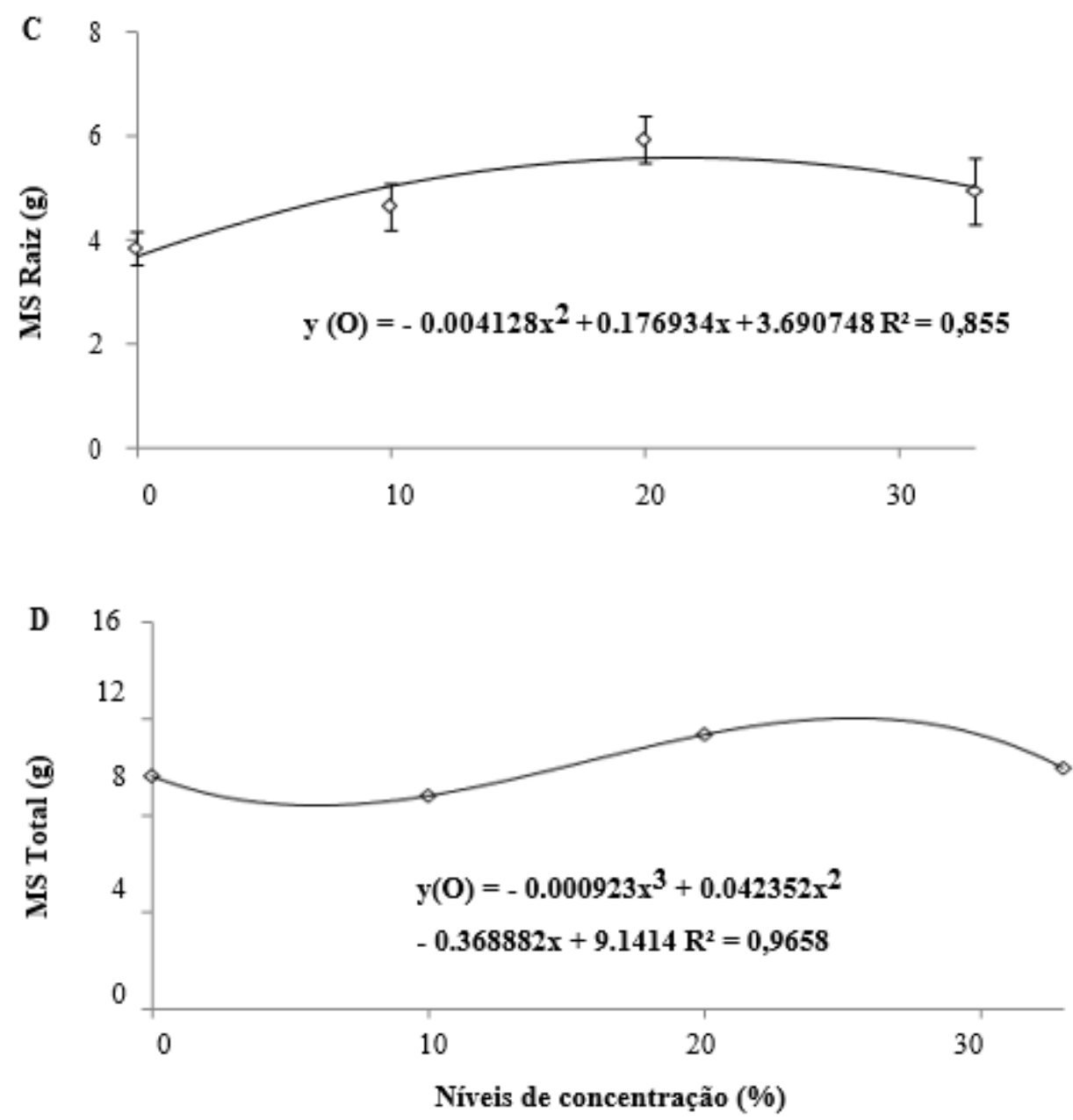

\section{Análises com borra de café (BC)}

\section{Altura (H) e diâmetro do caule (DC)}

Analisando o parâmetro altura $(\mathrm{H})$ nos substratos contendo BC (Figura 4A) observa- se que as mudas de Moringa oleifera Lam apresentam melhor média de altura na testemunha (apenas solo) quando comparado aos tratamentos com BC. O tratamento $\mathrm{T} 0=100 \%$ solo obteve altura de $46,34 \mathrm{~cm}$, havendo queda brusca desta variável para $12,77 \mathrm{~cm}$ com o incremento de $33 \%$ BC, visualizando-se uma correlação decrescente explicada pelo coeficiente de determinação $\mathrm{R}^{2}(0,981)$. A testemunha demonstrou maior desempenho e qualidade das mudas, apresentando percentual de altura média de 39,09\%; 50,33 e 72,43\% maior do que nas concentrações de 10, 20 e $33 \%$ de BC respectivamente, aos 63 dias após plantio (DAP).

Quando observado o diâmetro do caule, notou-se influência negativa no uso da BC, uma vez que, quanto maior a concentração, menor o diâmetro, semelhante ao ocorrido com a altura (Figura 4A e B). Na testemunha (apenas solo) o diâmetro 
apresentou $9,93 \mathrm{~cm}$ foi reduzido para $2,97 \mathrm{~cm}$, o que corresponde a um decréscimo de $70,9 \%$ quando utilizado a concentração de $33 \%$ de BC, comparadas no $63^{\circ}$ (DAP).

Figura 4. Altura (A) e Diâmetro do caule (B) das plantas de Moringa oleíferaLam, submetidas a substratos com diferentes concentrações $(0,10,20$ e $33 \%)$ de borra de café. Regressão com:**significativo $(\mathrm{P}<0,05)$.

Figure 4. Height (A) and stem diameter (B) of the Moringa oleiferaLam plants, submitted to substrates with different concentrations $(0,10,20$ and 33\%) of coffee grounds. Regression with: $* *$ significant $(\mathrm{P}<0.05)$.
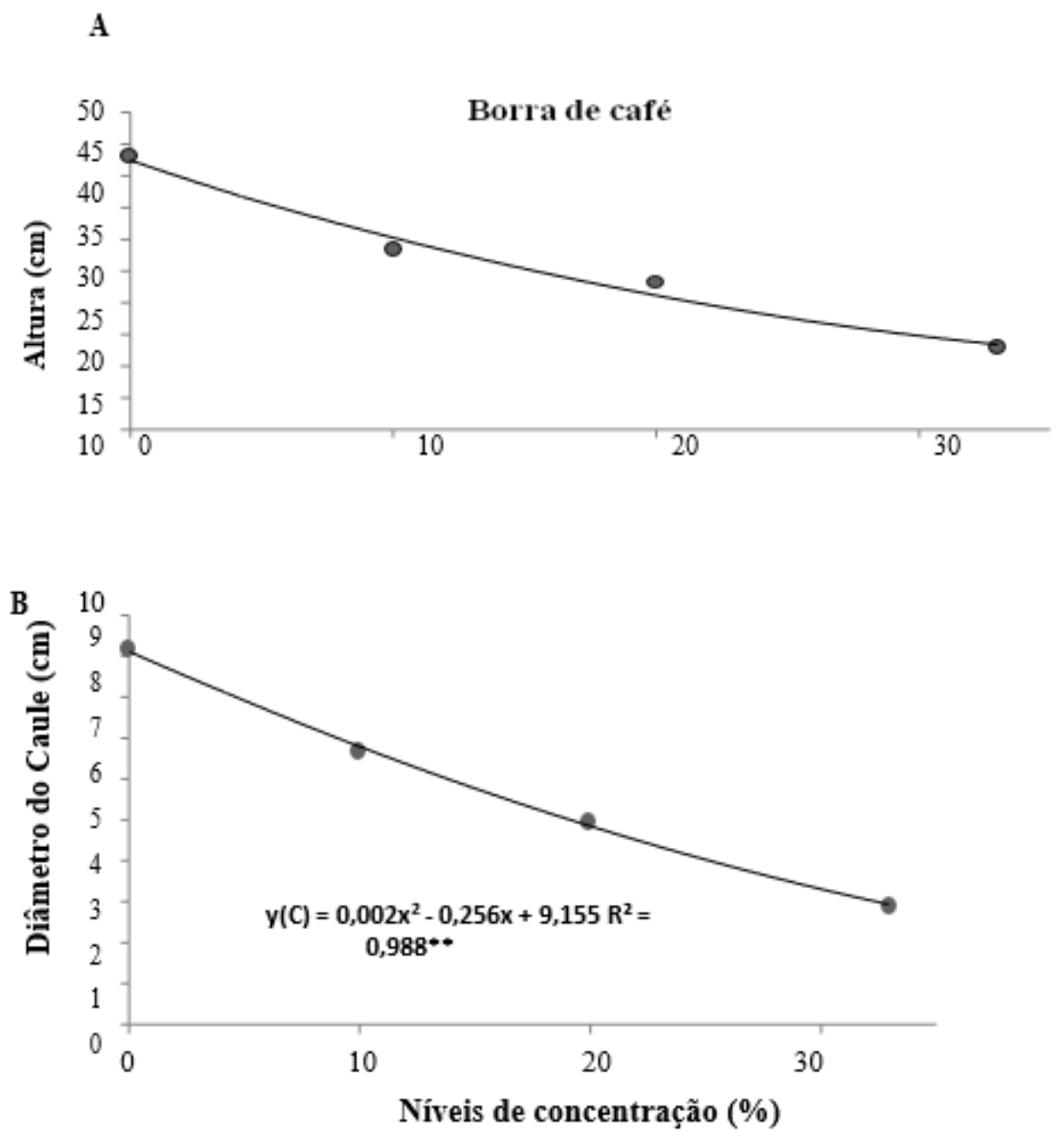

\section{Área foliar (AF) e comprimento de raiz (CR)}

Os substratos contendo BC usado nas análises do desenvolvimento inicial proporcionam diminuição contínua da área foliar, ocorrendo declínio de $587 \mathrm{~cm}^{2}$ para $33,28 \mathrm{~cm}^{2}$, encolhendo em $94,33 \%$ de área com o uso de $33 \%$ de concentração da BC, configurando uma correlação negativa, demonstrada pelo $\mathrm{R}^{2}(0,978)$ (Figura 5A).

Para o comprimento da raiz destaca-se a utilização de $10 \%$ de $\mathrm{BC}$, que elevou em $28,28 \%$ esta variável comparada a testemunha $\mathrm{P}(<0,05)$ (Figura $5 \mathrm{~B})$. 
Figura 5. Área foliar (A) e comprimento da raiz (B) das plantas de Moringa oleífera Lam, submetidas substratos com diferentes concentrações $(0,10,20$ e 33\%), de borra de café. Regressão com **: significativo $(\mathrm{P}<0,05)$.

Figure 5. Leaf area (A) and root length (B) of Moringa oleífera Lam plants, submitted to substrates with different concentrations $(0,10,20$ and 33\%), of coffee grounds. Regression with **: significant $(\mathrm{P}<0.05)$.

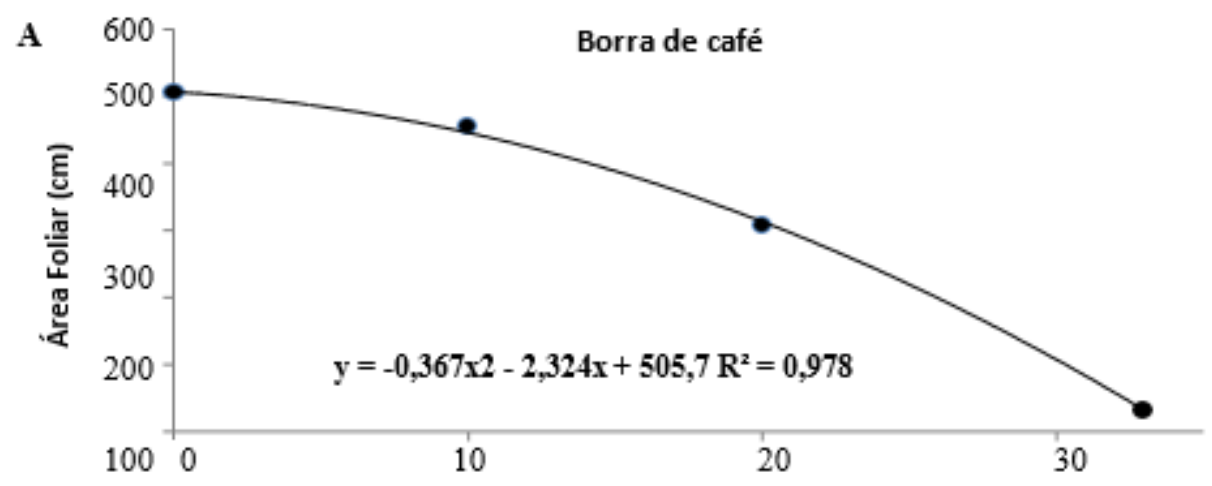

B

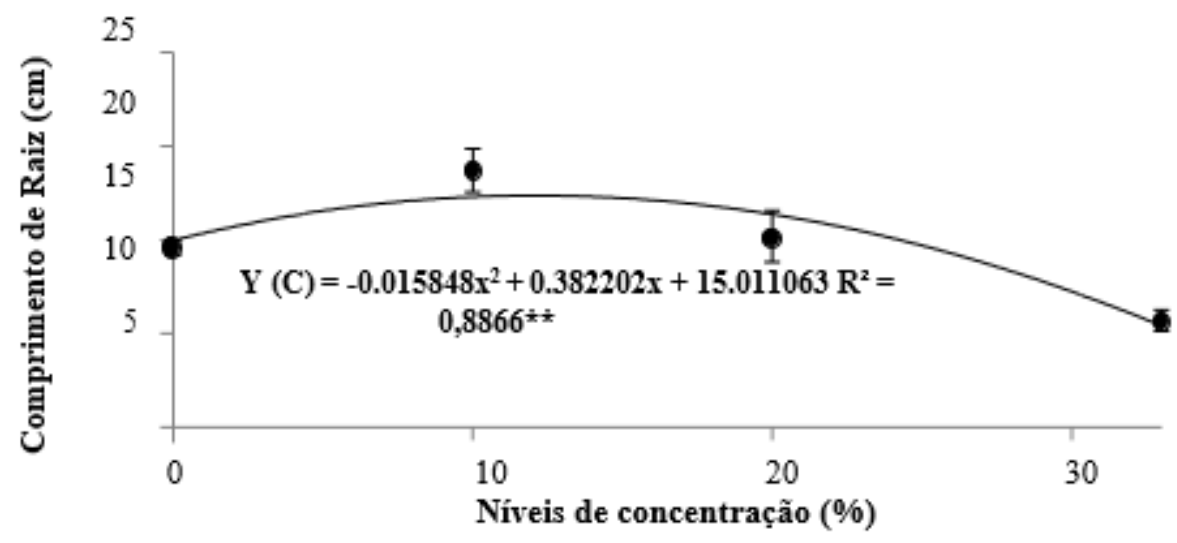

\section{Área foliar (AF) e comprimento de raiz (CR)}

Os substratos contendo BC usado nas análises do desenvolvimento inicial proporcionam diminuição contínua da área foliar, ocorrendo declínio de $587 \mathrm{~cm}^{2}$ para $33,28 \mathrm{~cm}^{2}$, encolhendo em $94,33 \%$ de área com o uso de $33 \%$ de concentração da BC, configurando uma correlação negativa, demonstrada pelo $\mathrm{R}^{2}(0,978)$ (Figura 5A).

Para o comprimento da raiz destaca-se a utilização de $10 \%$ de BC, que elevou em $28,28 \%$ esta variável comparada a testemunha $\mathrm{P}(<0,05)$ (Figura $5 \mathrm{~B})$.

Figura 5. Área foliar (A) e comprimento da raiz (B) das plantas de Moringa oleífera Lam, submetidas substratos com diferentes concentrações $(0,10,20$ e 33\%), de borra de café. Regressão com **: significativo $(\mathrm{P}<0,05)$. 
Figure 5. Leaf area (A) and root length (B) of Moringa oleífera Lam plants, submitted to substrates with different concentrations $(0,10,20$ and 33\%), of coffee grounds. Regression with **: significant $(\mathrm{P}<0.05)$.

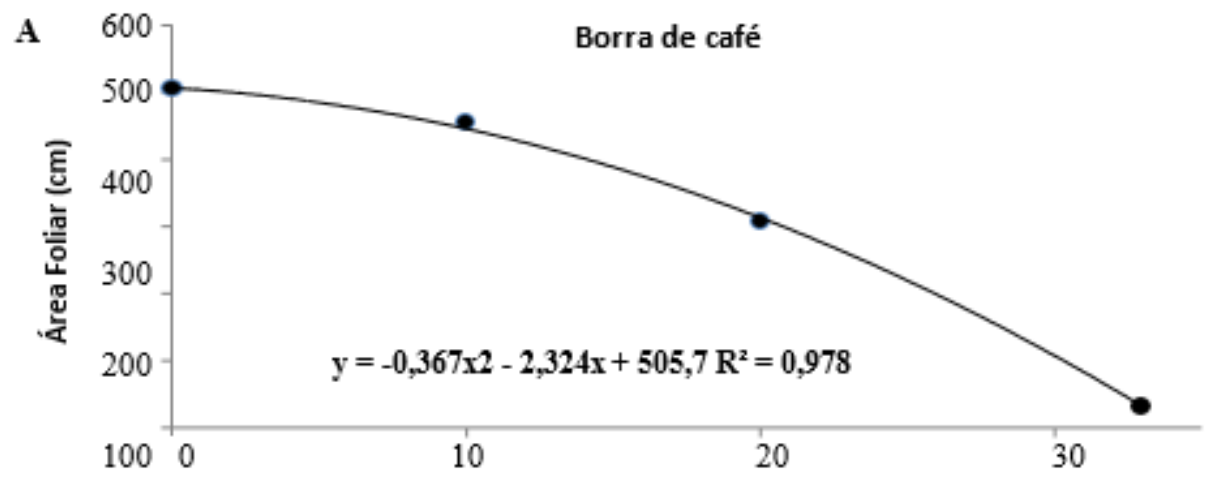

B

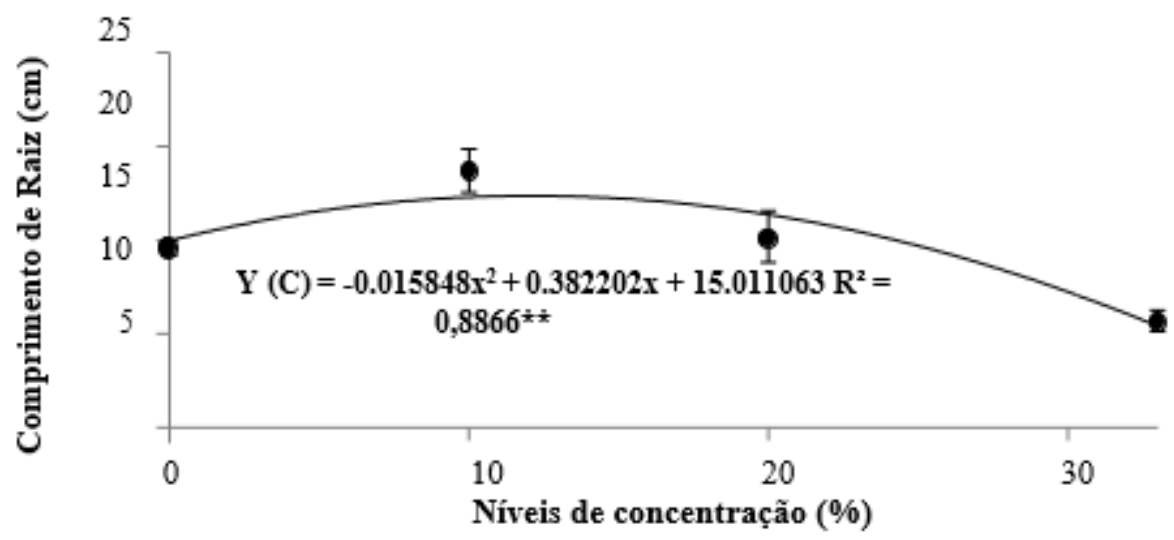

Teor de matéria seca do caule (TMSC), folha (TMSF) raiz (TMSR) e total (TMST)

A utilização da BC foi altamente prejudicial em todas as análises de massa seca, comportando-se de forma semelhante nestas analises, havendo declínio diretamente proporcional ao aumento da concentração. Ao observara figura 13A, observamos o declínio de TMSC de 2,79g para 0,08gcalculando perdas de 97,5\% de massa em detrimento à testemunha. No TMSF obtivemos percentuais de redução de $21,11 \% ; 39,84$ e 93,62\% nas concentrações de 10, 20 e 33\% de BF (Figura 13B). Para a TMSR o substrato ocasionou decadência de 31,59\%; 59,79 e 68,92\% (Figura 6C), e por fim comprometendo a planta de moringa que perdeu $85,08 \%$ da sua matéria seca total (TMST) (Figura 6D).

Figura 6. Teor de matéria seca do caule (TMSC) (A), folhas (TMSF) (B), raiz (TMSR) (C) e matéria seca total (TMST) (D) de Moringa oleíferaLam, submetidas substratos com diferentes concentrações $(0,10,20$ e $33 \%)$, de borra de café. Regressão com **: significativo $(\mathrm{P}<0,05)$. 
Figure 6. Stem dry matter content (TMSC) (A), leaves (TMSF) (B), root (TMSR) (C) and total dry matter (TMST) (D) of Moringa oleíferaLam, submitted to substrates with different concentrations $(0,10,20$ and 33\%), of coffee grounds. Regression with $* *$ : significant $(\mathrm{P}<0.05)$.

A

Borra de café

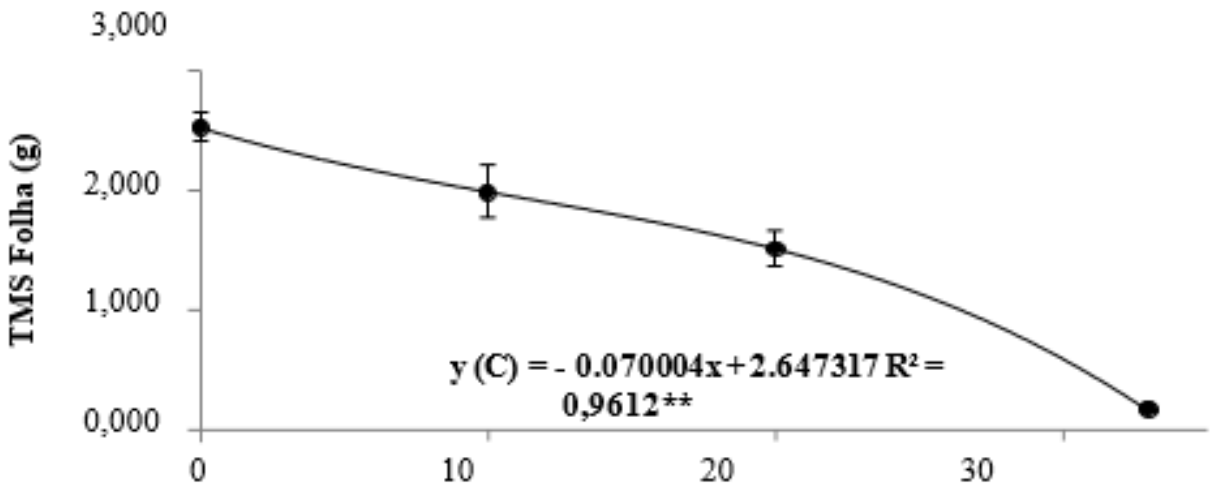

B
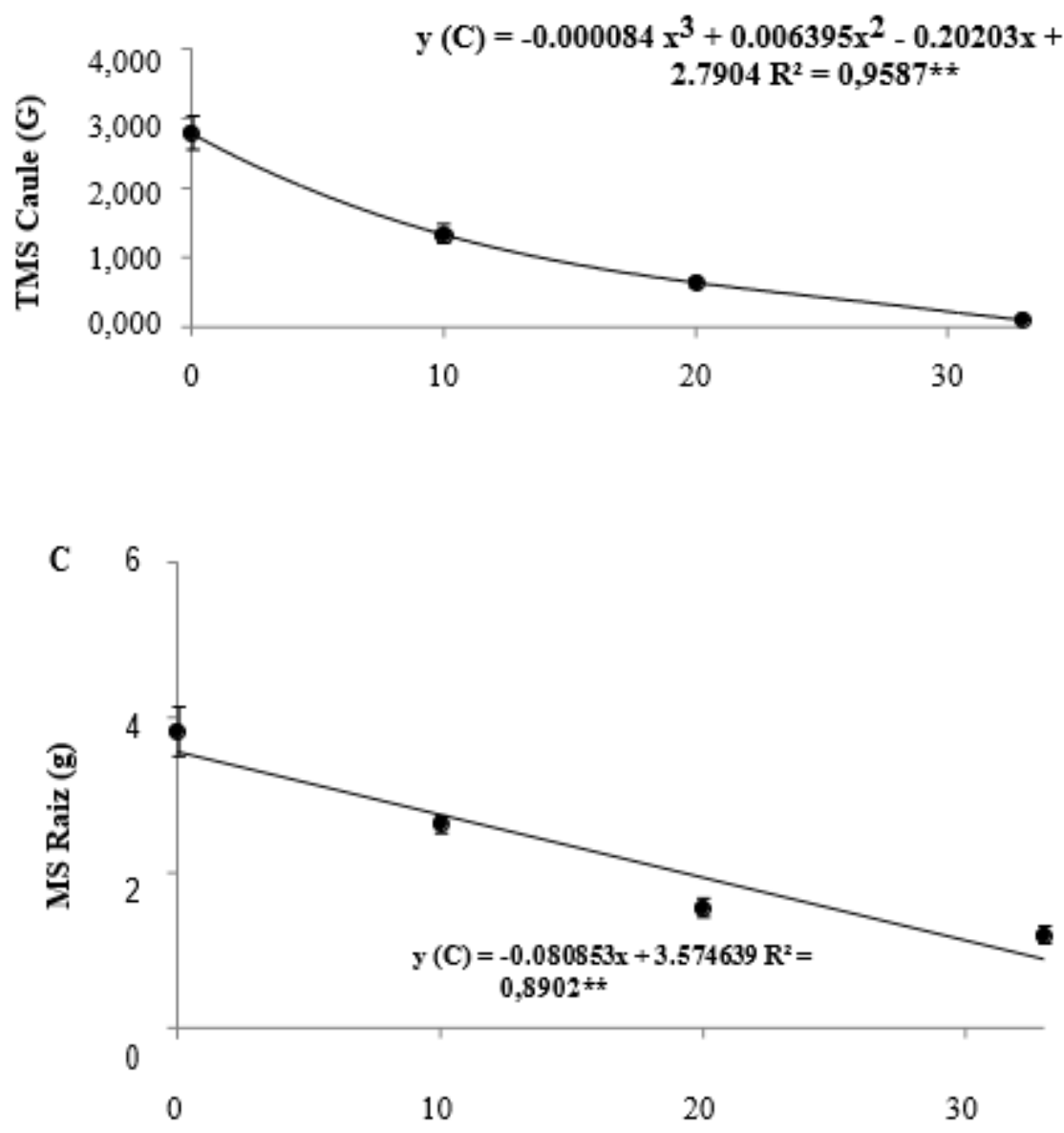


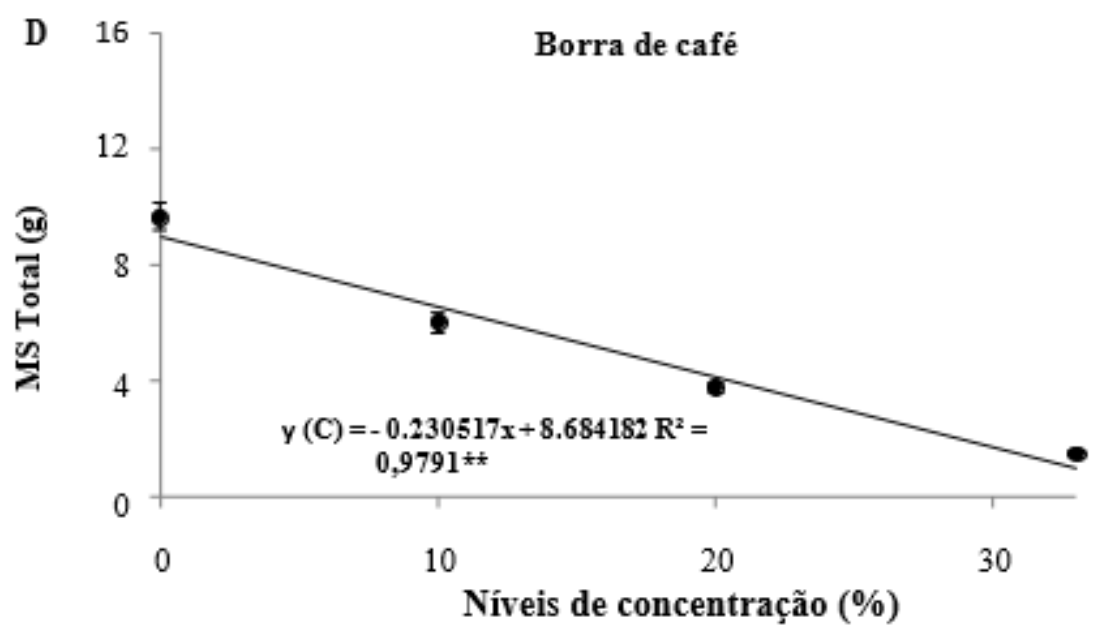

\section{DISCUSSÃO}

A hipótese de que haveria maior desenvolvimento inicial da espécie de moringa na concentração $33 \%$ esterco ovino (EO), foi recusada, tendo em vista que foram encontrados maiores incrementos, na concentração de $20 \%$, o que demonstra ser um bom indicativo para sua produção.

Uma provável explicação para tal resultado, é que a incorporação de esterco ovino em grandes quantidades pode se tornar prejudicial para a cultura em estudo, é sabido que o adubo orgânico tem o objetivo de melhorar a produção das culturas em geral, porém em quantidades que facilitem sua decomposição e mineralização. Possivelmente a incorporação de 33\% EO prejudicou a decomposição da matéria orgânica dificultando à disponibilização de nutrientes para plantas. Segundo [8], relata que estercos de caprino e ovino, possuem uma espécie de membrana que os revestem e torna-os duros quando excretados, possuem uma maior resistência à decomposição, sendo preciso saber as quantidades ideais de uso.

A literatura aponta vários fatores que podem interferir na decomposição e mineralização dos resíduos orgânicos, dentre estes, pode-se citar a relação C:N dos estercos, características físico-químicas e biológicas, além da temperatura e da umidade do solo. Alguns trabalhos realizados nessa vertente, também constaram que a mineralização de $\mathrm{N}$ em estercos caprinos e ovinos proporcionou pouca alteração na concentração de $\mathrm{N}$ nos estercos em dezessete semanas de decomposição, demonstrando lenta degradação deste composto [9].

O teor de matéria orgânica encontrado no tratamento com $20 \%$ de $\mathrm{EO}=\mathrm{T} 2$, demonstra-se suficiente e essencial para o desenvolvimento das mudas da moringa, provavelmente esta quantidade promoveu uma boa decomposição da $\mathrm{MO}$, fazendo com 
que o $\mathrm{pH}$ aumentasse para 7,1; melhorando assim a disponibilidade de nutrientes para a planta no seu estágio inicial de crescimento. Contribuindo ainda, para a redução de alumínios trocáveis $\mathrm{Al}^{3}$, estes que são prejudiciais para as plantas, apresentando valor zero. Somando ainda ao fato de que este tratamento apresentou altos níveis de fósforo (P) no substrato, destacando-se dos demais tratamentos, causando supostamente um melhor incremento fisiológico na cultura em estudo, [10] trabalhando com omissão de nutrientes no substrato de moringa, constatou que a omissão de $\mathrm{P}$ no substrato houve diferença significativa na redução de matéria seca total, em comparação a omissão de outros nutrientes como $\mathrm{K}, \mathrm{N}, \mathrm{Mg}$, Ca e $\mathrm{S}$, evidenciando assim que o nutriente $\mathrm{P}$ é um dos mais importantes para o desenvolvimento dessa arbórea. Isso nos remete a ideia de que mais trabalhos precisam ser realizados, com o uso de concentrações de esterco ovino, para termos mais exatidão de sua quantificação de uso.

Ao contrário do esperado, as mudas de Moringa oleifera Lam não mostraram maior incremento estrutural nas menores concentrações de $\mathrm{BC}$, pelo contrário se mostraram menor em todos parâmetros avaliados. Isso demonstra que a BC "in natura" não é indicada como composição de substrato para produção de mudas. A possível explicação para esse resultado atribui-se ao fato de a $\mathrm{BC}$ deveria ser previamente compostada, caso contrário torna-se inapropriada para ser usada como fertilizante orgânico. Sabe-se que, a compostagem ajuda a estimular a decomposição da matéria orgânica, tornando-a estável e rica em nutrientes para a planta.

Por todos os aspectos citados, de forma geral pode-se dizer que tanto o EO quanto à $\mathrm{BC}$ foram influenciados pela velocidade de decomposição e consequentemente mineralização dos resíduos orgânicos, fator este que interfere diretamente na disponibilidade de nutrientes para as plantas. Vale a pena destacar que, quanto maior incorporação destes na formação do substrato, mais tempo será necessário para sua completa decomposição e posterior disponibilidade de nutrientes para as plantas.

\section{CONCLUSÃO}

Recomenda-se a produção de mudas de Moringa oleifera Lam com substrato de esterco ovino na concentração de $20 \%$. Em relação ao substrato composto com a borra de café, não indicamos sua incorporação no substrato (in natura) para produção da espécie em estudo. 
É importante fazer a ressalva de que, a incorporação de substratos alternativos para produção de mudas de espécies arbóreas, é considerada uma alternativa viável, tanto econômica, quanto ecológica, uma vez que com a sua utilização é possível reduzir o impacto no ambiente e melhorar o ecossistema agrícola.

\section{REFERÊNCIAS}

[1] FUGLIE, LJ. A Árvore Milagrosa: Moringa oleifera: Nutrição Natural para os Trópicos. Serviço Mundial da Igreja, Dakar, 68, 1999.

[2] GONÇALVES, J. L. M.; SANTERELLI, E.G.; NETO, S. P. M.; MANARA, M. P. Produção de mudas de espécies nativas: substrato, nutrição, sombreamento e fertilização. In: GONÇALVES, J. L. M.; BENEDETTI, V. (Eds.) Nutrição e fertilização florestal. Piracicaba: ESALQ/USP, p.309-350, 2000.

[3] BORTOLINI, M. F.; et. al. Crescimento de mudas de Gleditschia amorphoides Taub. produzidas em diferentes substratos. Ciência Florestal, Santa Maria, v.22, n.1, p.35-46, janmar., 2012.

[4] KÄMPF, A.N. Produção comercial de plantas ornamentais. Guaíba: Agropecuária, 2000 .

[5] SOUZA, H. A.; ROZANE, D. E.; AMORIM, D. A.; MODESTO, V. C.; NATALE, W. Uso fertilizante do subproduto da agroindústria processadora de goiabas: I - atributos químicos do solo. Revista Brasileira de Fruticultura, v. 36, p. 713-724. 2014.

[6] DUTRA, T. R.; MASSAD, M. D.; SARMENTO, M. F. Q.; OLIVEIRA, J. C. Emergência e crescimento inicial da canafístula em diferentes substratos e métodos de superação de dormência. Revista Caatinga, Mossoró, v. 25, n. 2, p. 65 - 71, 2012.

[7] FERREIRA, A, D. Influência da borra de café no crescimento e nas propriedades químicas e biológicas de plantas de alface (Lactuca sativa L.). Bragança 2011.

[8] PETERSEN SO; LIND AM; SOMMER SG. Nitrogen and organic matter losses during storage of cattle and pig manure. Journal of Agricultural Science 130:69-79, 1998.

[9] EGHBAlL, B.; WIENHOLD, B. J.; GILlEY, J. E.; EIGENBERG, R. A. Mineralization of ManureNutrients. Journal of Soiland Water Conservation, 57:469-473, 2002 . 
[10] VIEIRA, H.; CHAVES, L. H. G.; VIÉGAS, R. A. Acumulação de nutrientes em mudas de moringa (Moringa oleífera Lam) sob omissão de macronutrientes. Revista Ciência Agronômica, Fortaleza, v.39, n.01, p. 130-136, 2008.

Recebido em: 01/09/2021

Aprovado em: 20/09/2021

Publicado em: 27/09/2021 